\title{
Fear of pain and fear of falling among younger and older adults with musculoskeletal pain conditions
}

\author{
Ronald R Martin $\mathrm{PhD}^{1}$, Thomas Hadjistavropoulos $\mathrm{PhD}^{1,2}$, Donald R McCreary $\mathrm{PhD}^{3}$
}

\begin{abstract}
RR Martin, T Hadjistavropoulos, DR McCreary. Fear of pain and fear of falling among younger and older adults with musculoskeletal pain conditions. Pain Res Manage 2005;10(4):211-218.
\end{abstract}

BACKGROUND: The fear-avoidance model of pain accounts for the debilitating consequences of strong fear as a component of reactions to painful conditions (eg, movements become anxiety-provoking because they cause pain). The model, which is supported in the literature, posits that fear of pain interferes with recovery because it leads to avoidance of beneficial activity. Despite the high prevalence of pain among the elderly, investigations of fear of pain in this population are scarce. A related construct, fear of falling, has been studied among elderly (but not younger) adults as an age-specific concern.

OBJECTIVES: To examine the relationship between fear of pain and fear of falling. Specifically, it is hypothesized that fear of pain and fear of falling are distinct constructs. Moreover, the authors investigated whether fear of falling becomes more relevant with increasing age in a sample of seniors and younger adults with musculoskeletal conditions.

METHODS: A convenience sample of younger and older adult physiotherapy outpatients $(\mathrm{n}=226)$ receiving treatment for musculoskeletal conditions were recruited for the study. Fear of pain and fear of falling were assessed using self-report measures.

RESULTS: There were no age differences with respect to fear of pain and fear of falling. Regression analyses showed that fear of pain measures contribute substantial unique variance to the prediction of each other; however, they only make minor unique contributions to the prediction of fear of falling. Similar results were obtained through confirmatory analyses using structural modelling techniques.

CONCLUSIONS: The analyses supported the distinctiveness of fear of pain and fear of falling. Moreover, among physiotherapy outpatients with musculoskeletal pain conditions, fear of falling and fear of pain are distinct constructs that appear to represent the concerns of both seniors and younger pain patients.

Key Words: Elderly; Fear of falling; Fear of pain; Pain; Seniors

\section{La peur de la douleur et la peur de tomber chez les adultes âgés et plus jeunes souffrant de pathologies associées à des douleurs musculosquelettiques} HISTORIQUE : Le modèle d'évitement de la douleur lié à la crainte
sont responsables des conséquences débilitantes d'une peur intense en
réaction à des pathologies douloureuses (p. ex., des mouvements peuvent
devenir anxiogènes parce qu'ils provoquent des douleurs). Le modèle,
étayé dans la documentation scientifique, postule que la peur de la
douleur entrave la convalescence parce qu'elle incite à éviter des activités
bénéfiques. Malgré la forte prévalence de douleur chez les personnes
âgées, les explorations de la peur de la douleur sont rares au sein de cette
population. Un concept connexe, la peur de tomber, a été étudié chez les
personnes âgées (mais non chez les adultes plus jeunes) sous forme de
préoccupation propre à l'âge.
OBJECTIFS : Examiner le lien entre la peur de la douleur et la peur de
tomber. Nommément, on postule que la peur de la douleur et la peur de
tomber sont des concepts distincts. De plus, les auteurs se sont demandé si
la peur de tomber devient plus pertinente avec le vieillissement auprès
d'un échantillonnage d'adultes âgés et plus jeunes atteints de pathologies
musculosquelettiques.

MÉTHODOLOGIE : Un échantillon de commodité d'adultes ambulatoires âgés et plus jeunes $(n=226)$ traités en physiothérapie pour des pathologies musculosquelettiques a été recruté pour l'étude. La peur de la douleur et la peur de tomber ont été évaluées au moyen de mesures signalées par les répondants

RÉSULTATS : On ne remarquait aucune différence d'âge envers la peur de la douleur et la peur de tomber. Les analyses de régression ont démontré que les mesures de peur de la douleur s'associent à un écart substantiel unique de prédiction les unes des autres. Toutefois, leurs contributions uniques sont mineures à l'égard de la prédiction de la peur de tomber. Des résultats similaires ont été obtenus au moyen d'analyses de confirmation par des techniques de modélisation structurelle.

CONCLUSIONS : Les analyses appuient le caractère distinct de la peur de la douleur et de la peur de tomber. De plus, parmi les patients ambulatoires en physiothérapie atteints de pathologies associées à des douleurs musculosquelettiques, la peur de tomber et la peur de la douleur sont des concepts distincts qui semblent préoccuper tant les patients âgés que les plus jeunes souffrant de douleurs.
$\mathrm{P}$ ain is highly prevalent among seniors $(1,2)$, but this population has been under-represented in investigations of painrelated concerns. Although there is rising interest in studying such phenomena among older adults (3), many relevant issues affecting this population remain largely unexplored. The present study focuses on one such issue, namely, fear of pain.

\section{FEAR OF PAIN}

The fear-avoidance model of pain (4) was developed to account for the substantial long-term debilitating consequences of strong fear when it is a component of reactions to painful disease or injury. Asmundson and Wright (5) pointed out that the fear-avoidance model of pain postulates that injury leads to the

${ }^{1}$ Department of Psychology and ${ }^{2}$ Centre on Aging and Health, University of Regina, Regina, Saskatchewan; ${ }^{3}$ Department of Psychology, York University, Toronto, Ontario

Correspondence and reprints: Dr Thomas Hadjistauropoulos, Centre on Aging and Health and Department of Psychology, University of Regina, Regina, Saskatchewan S4S OA2. Telephone 306-585-4457, fax 306-331-2321, e-mail thomas.hadjistavropoulos@uregina.ca 
experience of pain, followed by an appraisal process. Specifically, the pain experience may be appraised as a temporary, nonthreatening event that may be confronted and overcome in an adaptive way that ultimately leads to recovery. Alternatively, the pain experience may be appraised as a permanent, threatening event that is managed in a maladaptive way (ie, a cycle of fear of pain and subsequent avoidance is initiated) that ultimately leads to further disability and negative consequences. These consequences include physical and psychological distress, subsequent limitations in activity and additional negative thoughts. Although physiological reactivity is initially a response to fear, it serves to maintain negative outcomes such as anxious apprehensions and avoidance of daily activities. In turn, such outcomes make further contributions to physiological reactivity. Overall, catastrophic cognitions, fear, anxiety, physiological reactivity, avoidance, deconditioning and further pain are self-maintaining responses that culminate in distress and disability (6).

A comprehensive review by Vlaeyen and Linton (7) examined a growing number of studies that provide support for the mechanisms outlined in fear-avoidance models. For example, among samples of adolescents, chronic musculoskeletal pain patients and adults with heterogeneous pain problems, higher levels of anxiety sensitivity have been shown to influence fear of pain, which subsequently influences escape and avoidance behaviour (8-10). Furthermore, there is increasing evidence suggesting that fear of pain may have a stronger influence on functional disability than measures of pain severity (11-15).

Pain-related fear (ie, fear of pain and/or pain-related movement), its consequences and the fear-avoidance model have been studied primarily among young adults. However, evidence indicating age differences in the way in which anxiety is processed is compelling and makes plausible the hypothesis that fear of pain will operate differently in later life. Most studies (16) have shown that prevalence rates for anxiety disorders decline in later life. Owens et al (17) demonstrated that older persons obtain lower scores on the Anxiety Sensitivity Index (18) than do younger adults, and older men tend to obtain lower Beck Anxiety Inventory Scores (19) than do younger men. The finding concerning the Anxiety Sensitivity Index is especially relevant because this measure is a predictor of painrelated attentional biases (20). Nevertheless, anxiety disorders remain a problem for a subset of seniors with their manifestations differing as a function of age. For example, in older persons, anxiety presents more often as somatic symptoms $(21,22)$.

\section{FEAR OF PAIN AND FEAR OF FALLING}

Falling is a high-risk event for seniors. Older persons require a disproportionately high number of resources for trauma care (23). Approximately one-quarter of those 65 to 74 years of age living in the community report at least one fall per year, and for community-dwelling seniors who are 75 years or older, the number increases to one-third $(24,25)$. Twenty per cent of falls result in fractures, soft tissue injuries, joint dislocations and persisting impairments $(26,27)$. Falls represent one of the leading causes of hospitalization for people over 65 years of age (28). Moreover, the death rate from falls increases significantly with age. A variety of physical and psychological risk factors for falling have been reported (29). Physical risk factors for falling include changes in the vestibular, somatosensory and visual systems of seniors, an orthopedic or cardiovascular diagnosis, the use of walking aids/devices, and confusion (30-32).
But, falls and fear of falling are not solely the result of physical factors and past falls $(33,34)$. Depression has also been associated with an increased risk of falls (32). Fear of falling or loss of confidence while engaging in physical activity has been reported in $50 \%$ to $60 \%$ of fallers from several different community samples $(27,35)$. Fear of pain may be an important factor in falling (eg, among the many seniors with musculoskeletal problems, fear of pain may be leading to avoidance of beneficial activity, which could result in deconditioning and, therefore, falls), although no published studies investigating this issue were found. A construct related to the fear of pain which has received some attention in the gerontological literature is 'fear of falling'. Between $25 \%$ and $33 \%$ of reported fallers acknowledge avoidance of activity because of fear of falling $(35,36)$. In fact, 'postfall syndrome' (associated with fear of falling) leads to activity restriction and loss of independence beyond that warranted by physical injuries resulting from the fall itself (37-39). Significant levels of fear of falling and activity restriction have also been observed in seniors who have not experienced any fall episodes or related injuries $(35,40)$. Paradoxically, people with a high fear of falling experience increased risk of falling and greater declines in activities of daily living over time (41). Declines in activities of daily living cannot be explained by a greater frequency of falls among those who have a high fear of falling. Those who have not fallen but who have a high fear of falling also have an increased risk of admission to an institution (41). Fear of falling is also related to a lower quality of life (42). Regular and appropriate exercise contributes to the prevention of falls among seniors, yet those who are afraid of falling (and indeed those who fear pain or movement) may avoid exercise $(30)$. Tinetti et al $(36,43,44)$ have argued that fear of falling represents a remediable independent contributor to functional decline. Numerous psychological and environmental factors are associated with fear of falling (eg, social support and not communicating about falls) $(34,45)$. Falls have been found to be a factor in $40 \%$ of nursing home admissions (46). Because the availability of support is a factor determining whether institutionalization will occur, those who cannot rely on family and friends may feel particularly vulnerable to losing their independence (34).

A main goal of the present investigation was to examine the relation between fear of falling and fear of pain among seniors and younger adults, and to assess these phenomena in each of these populations. It is proposed that the construct of fear of falling is distinct from, but related to, fear of pain. Fear of pain is, in many ways, a broader construct than fear of falling because many activities that are avoided as a result of fear of pain are not related to falling (eg, turning one's head while sitting and bending one's elbow).

A second goal of the present study was to determine whether there are age differences in experiencing fear of pain and fear of falling among patients treated for musculoskeletal pain conditions in physiotherapy clinics. If age differences were present, then age-appropriate normative data would be necessary for the clinical assessment of fear of pain among physiotherapy populations of seniors (47). Consistent with previous research that has demonstrated age-related reductions in anxiety levels, it was hypothesized that fear of pain may be less intense among seniors than younger persons. Further, based on previous research $(36,48)$, it was also anticipated that fear of falling is an age-specific concern that is present mainly in seniors. 
TABLE 1

Participant demographic information

\begin{tabular}{|c|c|c|c|c|c|c|}
\hline \multirow[b]{2}{*}{ Measure } & \multicolumn{6}{|c|}{ Age group, years } \\
\hline & 18 to 29 & 30 to 39 & 40 to 49 & 50 to 59 & 60 to 69 & 70 to 100 \\
\hline \multicolumn{7}{|l|}{ Number $(n=226)$} \\
\hline Women & 23 & 13 & 27 & 24 & 20 & 14 \\
\hline Total & 40 & 33 & 49 & 39 & 36 & 29 \\
\hline Age (years), mean (SD) & $23.70(3.62)$ & $34.88(3.21)$ & $44.33(2.88)$ & $54.21(3.04)$ & $64.31(2.41)$ & $77.17(4.88)$ \\
\hline \multicolumn{7}{|l|}{ Marital status, $\mathrm{n}$} \\
\hline Single & 32 & 8 & 8 & 1 & 1 & 0 \\
\hline Married & 5 & 17 & 31 & 30 & 28 & 20 \\
\hline Separated/divorced & 3 & 8 & 8 & 6 & 3 & 2 \\
\hline Widowed & 0 & 0 & 1 & 2 & 3 & 7 \\
\hline Falls Efficacy Scale & $93.83(12.32)$ & $90.18(13.80)$ & $92.16(21.34)$ & $86.41(18.17)$ & $90.97(24.69)$ & $85.55(17.86)$ \\
\hline \multicolumn{7}{|l|}{ Pain-related fear, mean (SD) } \\
\hline Pain Anxiety Symptoms Scale & $68.73(37.24)$ & $66.79(37.70)$ & $61.54(28.57)$ & $68.45(31.96)$ & $65.32(35.40)$ & $52.71(30.41)$ \\
\hline Tampa Scale for Kinesiophobia & $37.91(7.84)$ & $38.00(8.06)$ & $39.17(6.43)$ & $37.91(6.34)$ & $37.02(7.48)$ & $36.23(4.60)$ \\
\hline Fear of Pain Questionnaire - Third Edition & $74.23(25.48)$ & $71.08(22.36)$ & $72.92(19.21)$ & $75.34(24.71)$ & $67.94(19.95)$ & $76.38(22.29)$ \\
\hline
\end{tabular}

${ }^{*}$ A modified version of the Activities-specific Balance Confidence Scale with a zero to 100 scale was used

TABLE 2

Number and percentage of participants within each age group who reported pain in specific regions of the body

\begin{tabular}{|c|c|c|c|c|c|c|c|c|c|}
\hline $\begin{array}{l}\text { Age group, } \\
\text { years }\end{array}$ & $\begin{array}{l}\text { Head, face } \\
\text { and mouth, } \\
\text { n (\%) }\end{array}$ & $\begin{array}{l}\text { Cervical } \\
\text { region, } \\
\text { n (\%) }\end{array}$ & $\begin{array}{c}\text { Upper shoulders } \\
\text { and upper limbs, } \\
n(\%)\end{array}$ & $\begin{array}{c}\text { Thoracic } \\
\text { region, } \\
\text { n (\%) }\end{array}$ & $\begin{array}{l}\text { Abdominal } \\
\text { region, } \\
\text { n (\%) }\end{array}$ & $\begin{array}{c}\text { Lower back, } \\
\text { lumbar spine, } \\
\text { sacrum and coccyx, } \\
\mathbf{n}(\%)\end{array}$ & $\begin{array}{l}\text { Lower limbs, } \\
\mathbf{n}(\%)\end{array}$ & $\begin{array}{l}\text { Pelvic } \\
\text { region, } \\
\text { n (\%) }\end{array}$ & $\begin{array}{c}\text { Anal, } \\
\text { perianal } \\
\text { and genital, } \\
\mathbf{n}(\%)\end{array}$ \\
\hline 18 to $29(n=40)$ & $1(2.5)$ & $5(12.5)$ & $13(32.5)$ & $5(12.5)$ & $0(0.0)$ & $13(32.5)$ & $17(42.5)$ & $2(5.0)$ & $0(0.0)$ \\
\hline 30 to $39(n=33)$ & $2(6.1)$ & $3(9.1)$ & $15(45.5)$ & $6(18.2)$ & $2(6.1)$ & $14(42.4)$ & $9(27.3)$ & $4(12.1)$ & $0(0.0)$ \\
\hline 40 to $49(n=49)$ & $0(0.0)$ & $15(30.6)$ & $19(38.8)$ & $9(18.4)$ & $0(0.0)$ & $16(32.7)$ & $18(36.7)$ & $1(2.0)$ & $0(0.0)$ \\
\hline 50 to $59(n=39)$ & $1(2.6)$ & $5(12.8)$ & $11(28.2)$ & $3(7.7)$ & $0(0.0)$ & $15(38.5)$ & $18(46.2)$ & $5(12.8)$ & $0(0.0)$ \\
\hline 60 to $69(n=36)$ & $0(0.0)$ & $10(27.8)$ & $17(47.2)$ & $1(2.8)$ & $0(0.0)$ & $9(25.0)$ & $14(38.9)$ & $6(16.7)$ & $0(0.0)$ \\
\hline 70 to $100(n=29)$ & $0(0.0)$ & $5(17.2)$ & $10(34.5)$ & $5(17.2)$ & $0(0.0)$ & $6(20.7)$ & $14(48.3)$ & $4(13.8)$ & $0(0.0)$ \\
\hline Total sample $(n=226)$ & $4(1.8)$ & $43(19.0)$ & $85(37.6)$ & $29(12.8)$ & $2(0.9)$ & $73(32.3)$ & $90(39.8)$ & $22(9.7)$ & $0(0.0)$ \\
\hline
\end{tabular}

\section{METHODS}

Participants and procedure

Following approval from the Research Ethics Board of the University of Regina, Regina, Saskatchewan, 299 physiotherapy outpatients were invited to participate in the present study. Seventy-three of these individuals either did not return the questionnaire package or refused to participate (ie, the participation rate was $76 \%)$. As such, participants $(n=226)$ represented a convenience sample of adult physiotherapy outpatients of various ages who were receiving treatment for musculoskeletal conditions.

Front desk clinic staff were asked to recruit consecutive outpatients that corresponded to the age groups listed in Table 1. Participants received $\$ 10.00$ for taking part in the study. For a further description of participant demographic information see Table 1 . All participants signed consent forms and were informed about the voluntary nature of participation.
Participants provided information about the location of their pain by using a diagram of the human body that was sectioned to identify discrete areas (eg, lower limbs, thoracic region), which allowed for a reliable scoring procedure (49). The number and percentage of participants within six different age groups (18 to 29,30 to 39,40 to 49,50 to 59,60 to 69 and 70 to 100 years of age) who self-reported pain in specific body regions are presented in Table 2. Across all participants, the average duration of the selfreported pain problem(s) was 29 weeks (ranging from one week to 6.9 years). Few participants (2.2\%) reported multiple (ie, more than three) pain sites.

Pain measures

Pain Severity Subscale of the Multidimensional Pain Inventory: Using the Pain Severity Subscale of the Multidimensional Pain Inventory (50), respondents rated their pain levels at the present 


\section{TABLE 3}

Descriptive statistics for fear of falling measures and pain-related fear

\begin{tabular}{lcc}
\hline & Mean & SD \\
\hline Fear of falling measures & & \\
Activities-specific Balance Confidence Scale* & 80.10 & 23.52 \\
Falls Efficacy Scale & 90.13 & 18.69 \\
Pain-related fear measures & & \\
Pain Anxiety Symptoms Scale & 64.24 & 33.55 \\
Tampa Scale for Kinesiophobia & 37.89 & 6.97 \\
Fear of Pain Questionnaire - Third Edition & 72.94 & 22.21 \\
\hline
\end{tabular}

${ }^{*}$ A 0 to 100 scale was used in this study

time and over the past week. Respondents were also asked to rate how much suffering they have experienced due to their pain. All items within this subscale involved a rating scale of zero to six, with higher scores indicating greater levels of pain and suffering. The scale has been shown to be valid and reliable (50).

\section{Pain-related fear measures}

All of the following measures have demonstrated satisfactory psychometric properties $(13,51,52)$.

Tampa Scale for Kinesiophobia: Using the Tampa Scale for Kinesiophobia (TSK) (51), respondents indicated their level of agreement with 17 items (eg, "If I were to try to overcome it [my situation], my pain would increase") using a scale ranging from one (strongly disagree) to four (strongly agree). High scores were indicative of high levels of fear.

Pain Anxiety Symptoms Scale: Using the Pain Anxiety Symptoms Scale (PASS) (13), respondents were asked to indicate how often they engage in 40 pain-related thoughts (eg, "When I feel pain, I become afraid of dying") and activities (eg, "When I feel pain, I try to stay as still as possible") using a scale ranging from zero (never) to five (always). High scores were indicative of high levels of fear.

Fear of Pain Questionnaire - Version III: Using the Fear of Pain Questionnaire - Version III (FPQ-III) (52), in response to 30 items (eg, "having a muscle cramp"), respondents were asked to indicate how fearful they are (or would be), using a scale ranging from one (not at all) to five (extreme). High scores were indicative of high levels of fear.

\section{Fear of falling measures}

Each of the following measures have satisfactory psychometric properties $(36,48)$.

Falls Efficacy Scale: Using the Falls Efficacy Scale (FES) (36), respondents were asked to rate their confidence in carrying out activities (eg, dressing) without falling using a scale ranging from one (not at all confident) to 10 (extremely confident). High scores were indicative of high levels of efficacy (ie, low levels of fear of falling). Activities-specific Balance Confidence Scale (ABC) (48): Using the Activities-specific Balance Confidence Scale (ABC) (48), respondents were asked to rate their degree of confidence (zero to 100 scale) in maintaining their balance while performing 16 activities (eg, "How confident are you that you can maintain your balance and remain steady when you sweep the floor"). The overall score represented an average of all the items on the scale. High scores were indicative of high levels of confidence (ie, low levels of fear of falling).

\section{RESULTS}

The means and SDs for all of the fear of falling and fear of pain measures are presented in Table 3. Before proceeding with the analysis of the fear of pain and fear of falling measures, the authors wanted to determine whether there were any age differences regarding pain intensity (Table 1 ) in the sample of physiotherapy outpatients. The age groups listed in Table 1 were compared with respect to scores on the Multidimensional Pain Inventory, using one-way ANOVA. The results did not reveal any age effects $(\mathrm{F}[5,220]=0.28, \mathrm{P}<0.05)$.

Are fear of pain and fear of falling age-specific concerns? Analyses regarding age differences in the fear of pain and fear of falling measures were investigated by partitioning participant age into six groups (ie, 18 to 29,30 to 39,40 to 49,50 to 59, 60 to 69 and 70 to 100 years of age). The sizes of the various age groups are shown in Table 1 . A six by two (age group by sex) Multivariate Analysis of Variance (MANOVA) was conducted using the fear of falling scores as the dependent measures. Using the Wilks criterion, no significant main effects were observed based on age $(\mathrm{F}[10,412]=1.13, \mathrm{P}>0.05)$, or sex $(F[2,205]=0.75, P>0.05)$. In addition, the interaction effect was not significant $(\mathrm{F}[10,412]=1.73, \mathrm{P}>0.05)$. Further, a six by two (age group by sex) MANOVA was performed using the pain-related fear scores as dependent measures. No significant main effects (Wilks criterion) were observed for age $(F[15,522]=0.81, \mathrm{P}>0.05)$ or $\operatorname{sex}(\mathrm{F}[3,172]=1.12, \mathrm{P}>0.05)$. The interaction was not significant $(\mathrm{F}[15,522]=1.28, \mathrm{P}>0.05)$. Consistent with the MANOVA results, the correlations of age with the fear of falling and pain-related fear variables were not significant (Table 4).

Regression analyses: Are fear of pain and fear of falling distinct constructs?

To determine the extent to which fear of falling measures were distinct from the pain-related fear measures, a series of regression analyses were conducted. The intercorrelations among

\section{TABLE 4}

Intercorrelations among age and all dependent measures, $r(P)$

\begin{tabular}{|c|c|c|c|c|c|c|}
\hline & Age & $A B C$ & FES & PASS & TSK & FPQ-III \\
\hline$\overline{\text { Age }}$ & - & $-0.20(<0.004)$ & $-0.13(0.051)$ & $-0.10(0.12)$ & $-0.06(0.43)$ & $0.01(0.90)$ \\
\hline$A B C$ & - & - & $0.56(<0.001)^{\star}$ & $-0.38(<0.001)^{*}$ & $-0.36(<0.001)^{\star}$ & $-0.12(0.087)$ \\
\hline FES & - & - & - & $-0.43(<0.001)^{\star}$ & $-0.33(<0.001)^{\star}$ & $-0.078(0.25)$ \\
\hline PASS & - & - & - & - & $0.58(<0.001)^{\star}$ & $0.35(<0.001)^{\star}$ \\
\hline TSK & - & - & - & - & - & $0.37(<0.001)^{\star}$ \\
\hline FPQ-III & - & - & - & - & - & - \\
\hline
\end{tabular}

${ }^{*}$ Significant at the 0.001 level. ABC Activities-specific Balance Confidence Scale; FES Falls Efficacy Scale; FPQ-III Fear of Pain Questionnaire - Version III; PASS Pain Anxiety Symptoms Scale; TSK Tampa Scale for Kinesiophobia 
TABLE 5

Full-model regression analyses and regression analyses predicting fear of falling measures from pain-related fear measures and vice versa

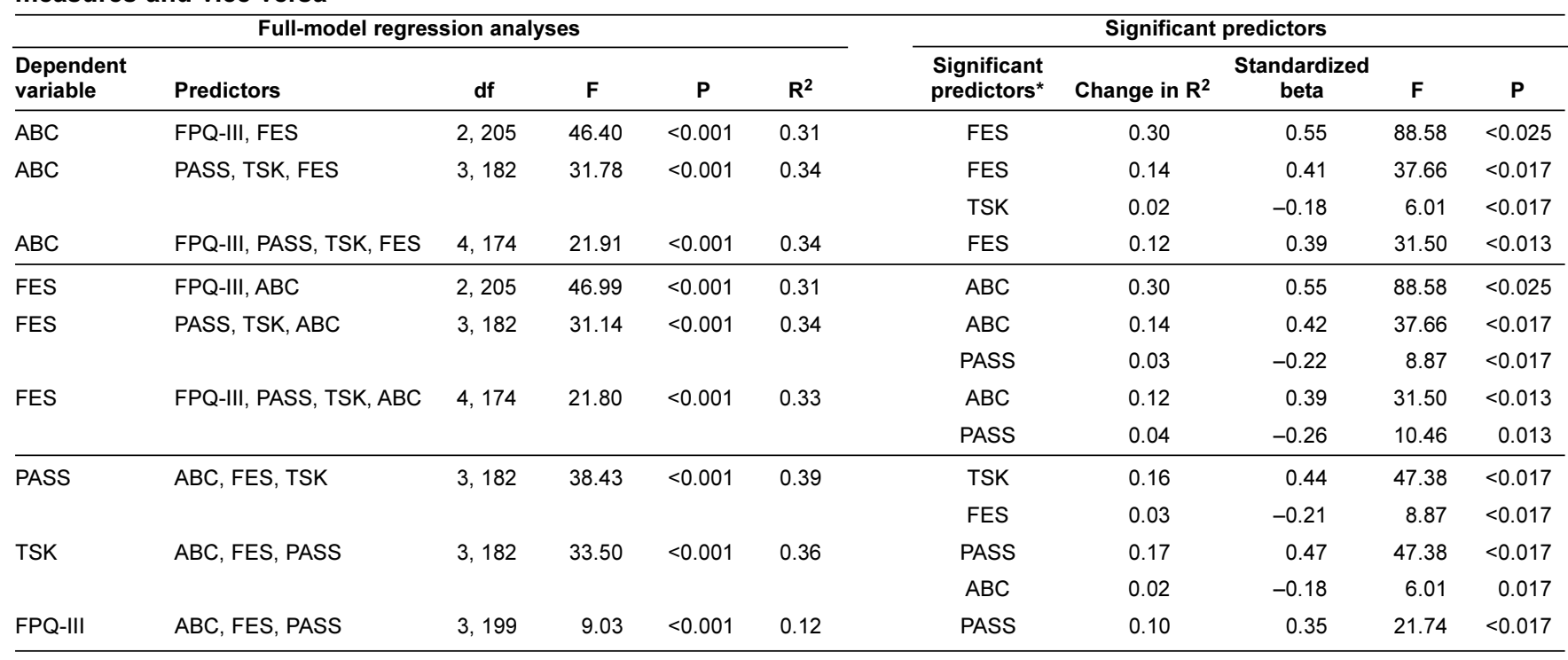

*Predictors that made independent and unique contributions to the equation after all other variables were entered. ABC Activities-specific Balance Confidence Scale; FES Falls Efficacy Scale; FPQ-III Fear of Pain Questionnaire - Version III; PASS Pain Anxiety Symptoms Scale; TSK Tampa Scale for Kinesiophobia

the variables that were used in the regressions are presented in Table 4. The aim of these regressions was to assess the relative power of each pain-related fear and fear of falling measure in predicting other pain-related fear and fear of falling measures. A conservative strategy was used in conducting the regression analyses. First, the full model was tested for each regression equation. A Bonferroni correction was used to control for familywise error rates. Specifically, the full regression model in each regression was tested at an alpha level of 0.006 (ie, 0.05 divided by nine). Second, if the full model was significant, each predictor's unique contribution to the regression was examined after all other predictors were entered into the equation. Again, a Bonferroni correction was applied, that is, the alpha level for examining the unique contribution of each predictor was determined by dividing 0.05 by the total number of predictors in the equation (to minimize the probability of type I errors). For example, in the equation involving the prediction of ABC scores using the FPQ-III, PASS, TSK and FES, the alpha value was set to 0.013 (ie, 0.05 divided by four predictors). The results of these analyses are presented in Table 5 .

Overall, the regression results indicated that when using a fear of falling measure as the criterion, the fear of pain measures only made minor unique contributions to the prediction equation. In contrast, the other fear of falling measure made substantial unique contributions to the prediction. Similarly, when using a fear of pain measure as the criterion, the fear of falling measures accounted for smaller significant changes in the $\mathrm{R}^{2}$ value. In contrast, other fear of pain measures contributed larger significant changes in the $\mathrm{R}^{2}$ value. The regressions, therefore, support the distinctiveness of the constructs of fear of pain and fear of falling.

Confirmatory analysis: Are fear of pain and fear of falling distinct constructs?

A confirmatory analysis was conducted using a structural modelling procedure to determine both the degree to which the items on each of the five scales loaded onto their respective constructs, and the correlations between the latent variables. These types of correlations are more accurate estimates of the true association between pairs of variables for two reasons: first, they assess each relationship after the measurement error has been removed from the observed variables; and second, they determine each correlation in a multivariate environment. For example, the correlation between the latent FES and PASS scores will represent the association between the two variables after the influence of all the other variables has been controlled for.

There are two components to this analysis. The first uses confirmatory factor analysis to create the measurement model. This phase of the analysis will often use the individual items from each scale to create the latent constructs. However, there is a minimum case to estimated parameter ratio of 5:1. That is, for each estimated parameter, there must be at least five cases. If individual items are used to create the measurement model for this analysis, at least 1130 respondents (ie, 113 items across all five scales, multiplied by two estimated parameters each, multiplied by the minimum of five cases per estimated parameter) would be required to establish the measurement model. In such instances, item parcels are used to create the latent factors. This is performed either by grouping items randomly into at least three indicators per latent factor or, when available, by using the specified subscales for a latent factor. In this instance, three random indicator parcels for the FES, ABC and TSK were created; and the four PASS subscales and the three FPQ-III subscales were used to create the PASS and FPQ-III latent factors, respectively. Once the measurement model was identified, correlational paths between each of the five latent factors were put in place.

The analysis was performed using EQS version 6.1 (Multivariate Software Inc, USA) (53), and followed the procedures outlined by Byrne (54). Raw data were used as input, along with a maximum likelihood estimation procedure. Following the recommendations by $\mathrm{Hu}$ and Bentler (55), model fit was determined by using the following indices: $\chi^{2}$ (values should not be significant); $\chi^{2}$ to $\mathrm{df}$ ratio (values should be less 


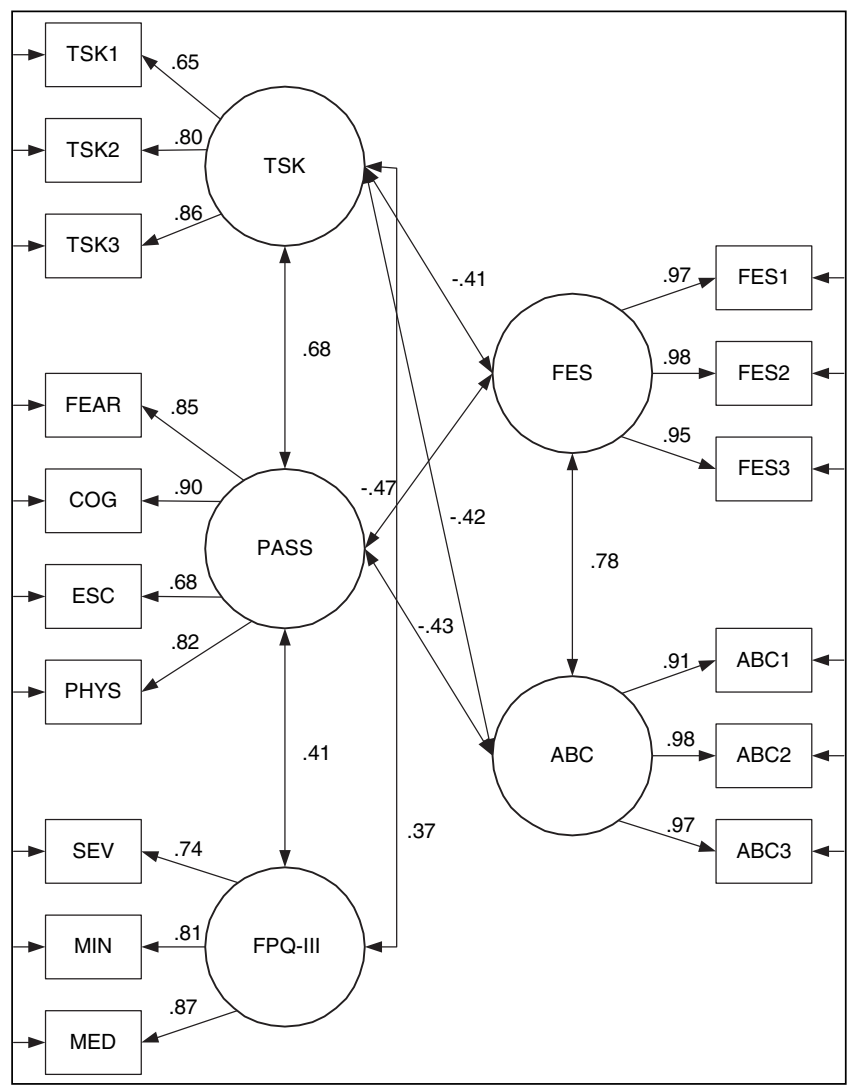

Figure 1) Final structural model. Large circles are latent constructs, rectangles are observed variables, short lines with single-headed arrows aimed toward rectangles represent error terms, longer lines with singleheaded arrows that go between circles and rectangles represent factor loadings, and double-headed arrows are correlational paths. All given parameter estimates are standardized and significant $(P<0.001)$. The four Pain Anxiety Symptoms Scale (PASS) subscales are fearful thoughts about pain (FEAR), cognitive anxiety (COG), escape and avoidance (ESC), and physiological anxiety (PHYS). The three Fear of Pain Questionnaire - Version III (FPQ-III) subscales are fear of severe pain (SEV), fear of minor pain (MIN) and fear of medical pain (MED). Item parcels were used for the Activities-Specific Balance Confidence scale (ABC), Falls Efficacy Scale (FES) and the Tampa Scale for Kinesiophobia (TSK) (see text)

than 2.0); the Comparative Fit Index (values should be close to 0.95 ); the root mean square error of approximation (values should be close to 0.06); and the standardized root mean square residual (values should be close to 0.08) (see also Browne and Cudeck [56], and Marsh et al [57]). Emphasis is placed on the latter four fit indices because $\chi^{2}$ statistics are inflated in larger samples (55).

The findings, represented in Figure 1, revealed an excellent fit between the proposed model and the observed data with $\chi^{2}[94]=130.73, \quad \mathrm{P}<0.007 ; \quad \chi^{2} / \mathrm{df}=1.39 ; \quad$ Comparative Fit Index $=0.99$; root mean square error of approximation $=0.04$; and standardized root mean square residual $=0.04$ (Figure 1 ). With regard to the measurement model, all item parcels or subscales loaded highly and significantly onto their respective latent factors $(\mathrm{P}<0.001)$. Thirteen of the 16 factor loadings were 0.80 or higher, while the remaining three loadings all were above 0.65 . Also, all five of the latent factor variances were statistically significant $(\mathrm{P}<0.001)$. Finally, all but two of the correlations among the latent factors were statistically significant; neither the latent FES nor ABC factors were correlated with the latent FPQ-III factor.

\section{DISCUSSION}

Perhaps the most fascinating conclusion that can be drawn from the data relates to the lack of a significant relationship (ie, correlation or group differences) between age and fear of falling in the sample of patients treated for musculoskeletal problems in a physiotherapy clinic. This was contrary to expectations. Fear of falling, in particular, is typically considered to be an age-specific concern affecting seniors, yet according to the data, when it comes to physiotherapy patients with musculoskeletal problems, it is as much of a concern among younger adults as it is among older persons. In fact, the absolute values of fear of falling measures were lower for older age groups of musculoskeletal patients. The lack of age-specific differences in the sample becomes even more interesting when viewed in the context of other recent findings involving nonclinical community samples (58), where fear of falling was discovered to be an age-specific concern that primarily affects seniors. That is, the presence of an injury or other musculoskeletal concern seems to account for the lack of age differences in the sample of physiotherapy outpatients. A possible alternative interpretation is that the sample of seniors obtained lower fear of falling scores than is typical. However, this is not the case. In a large longitudinal study (59) of community-dwelling seniors (drawn randomly from a directory of retirees in a mid-size Canadian city), the older adults obtained scores that were similar to the scores of senior participants (ie, within approximately half an SD). Moreover, the fear of falling means of the seniors in the present study (eg, ABC [using a 100-point scale] =80.10) were similar to those means obtained in a sample of older (ABC [using a 100-point scale] $=76.64$ ) and younger (ABC [using a 100point scale $]=90.60$ ) adults in other research (58). Furthermore, the means of the various fear of pain scores obtained in the present study (ie, TSK=37.89, PASS=64.24 and FPQ-III=72.94) were comparable to those found in other studies of adults with a narrower age range (eg, TSK=33.8 [60,61], FPQ-III=67.30 [61], PASS=68.7 [9]). Similar to other research (12), a relationship between sex and overall fear of pain scores was not found in the present study.

From a clinical perspective, the lack of age-specific differences in the present study has potential implications for clinical practice. Results suggest that there may be a need to assess pain-related fear and fear of falling among musculoskeletal pain patients (at least among those seeking physiotherapy), regardless of age. Although this may appear to run contrary to conventional clinical wisdom (ie, assessing fear of falling among younger patients), assessment procedures may be improved by assessing these constructs among adult pain patients of all ages. Self-report measures of pain-related fear and fear of falling are relatively easy to administer and score. Therefore, the addition of these measures to the assessment process would not represent an unreasonable demand on pain clinicians. However, assessing these constructs among adults of all ages may yield substantial benefits. The results of these assessments may provide valuable information that would directly inform case conceptualizations, especially with regard to the development and maintenance of chronic musculoskeletal pain conditions. Moreover, the results of these assessments would have direct treatment 
implications for cases involving high levels of pain-related fear or fear of falling. As it has been suggested elsewhere, pain patients with elevated self-reported, pain-related fear scores may be good candidates for psychological treatments that are designed to reduce these fears (62). This having been said, it would be premature to recommend the routine assessment of fear of pain and fear of falling until additional research supports the conclusions from this investigation.

From a theoretical perspective, the results support the idea that fear of falling and pain-related fear are related but distinct constructs. The FES and $\mathrm{ABC}$ account for substantial unique variance in the prediction of each other but only for small portions of the variance in the prediction of fear of pain scores. Analogous results were obtained for pain-related fear measures that only accounted for small portions of unique variance in the prediction of fear of falling.

The confirmatory analysis also supported the distinctiveness of fear of pain and fear of falling. Specifically, the 'item parcels' were loaded highly on their latent constructs, suggesting that there was minimal 'leftover variance' to share with other constructs. Furthermore, the latent constructs showed a stronger pattern of association within domain than across domains - that is the correlation between fear of pain and fear of falling measures either were not significantly different from zero or shared only approximately $20 \%$ of their variance. It is worth noting that these correlations were between latent factors and, as such, had the measurement error taken out of the analyses, making the correlations between latent constructs purer than the correlations between measured variables. The distinctiveness of pain-related fear and fear of falling measures suggest that it may be possible to increase the predictive ability of the fear avoidance model of pain by incorporating fear of falling concerns into the model.

\section{REFERENCES}

1. Parmelee PA, Smith B, Katz IR. Pain complaints and cognitive status among elderly institution residents. J Am Geriatr Soc 1993;41:517-22.

2. Roy R, Thomas M. A survey of chronic pain in elderly populations. Can Fam Physician 1986;32:513-6.

3. Hadjistavropoulos T. Introduction: Pain and aging. Pain Res Manag 2001;6:116-7.

4. Lethem J, Slade PD, Troup JD, Bentley G. Outline of a fear avoidance model of exaggerated pain perceptions. Behav Res Ther 1983;21:401-8.

5. Asmundson GJG, Wright KD. Biopsychosocial approaches to pain. In: Hadjistavropoulos T, Craig KD, eds. Pain: Psychological Perspectives. Hillsdale, New Jersey: Lawrence Erlbaum Associates, 2003:35-57.

6. Asmundson GJ, Norton PJ, Vlaeyen JWS. Fear-avoidance models of chronic pain: An overview. In: Asmundson GJG, Vlaeyen JWS, Crombez $G$, eds. Understanding and Treating Fear of Pain. New York: Oxford University Press, 2004:3-24.

7. Vlaeyen JW, Linton SJ. Fear-avoidance and its consequences in chronic musculoskeletal pain: A state of the art. Pain 2000;85:317-32.

8. Asmundson GJ, Taylor S. Role of anxiety sensitivity in pain-related fear and avoidance. J Behav Med 1996;19:577-86.

9. Muris P, Vlaeyen J, Meesters C. The relationship between anxiety sensitivity and fear of pain in healthy adolescents. Behav Res Ther 2001;39:1357-68.

10. Zvolensky MJ, Goodie JL, McNeil DW, Sperry JA, Sorrell JT. Anxiety sensitivity in the prediction of pain-related fear and anxiety in a heterogeneous chronic pain population. Behav Res Ther 2001;39:683-96.

11. Crombez G, Vervaet L, Lysens R, Baeyens F, Eelen P. Avoidance and confrontation of painful, back straining movements in chronic back pain patients. Behav Modif 1998;22:62-77.
A limitation of the present study relates to the convenience sample of patients treated for musculoskeletal problems. This sample may not necessarily be generalizable to all adults who have musculoskeletal problems because many such individuals do not receive active treatment for these conditions. The case may be that those who are in treatment have higher levels of pain and fear of pain/falling than those who have musculoskeletal problems and are not receiving any treatment. This assumption remains to be tested. Although the results do not support the need for age- or sex-specific fear of falling and fear of pain norms for patients with musculoskeletal problems, the findings of Williams et al (58) suggest that such norms may be necessary for nonclinical community samples. It would be important for future research to examine the need for normative data regarding fear of pain and fear of falling as a function of type of pain condition. This may be useful, given that fear of pain levels may vary depending on the type of pain condition (18). Another fruitful direction for future research would be to determine the impact of fear of falling in the rehabilitation of both seniors and younger adults and to test modified versions of the fear-avoidance model that takes into account fear of falling. Finally, it is important to acknowledge that although the present study involved a large number of participants, future research may be aimed at increasing sample sizes to ensure that age invariance exists in fear of pain and fear of falling measures, and to enhance the power of statistical analyses.

ACKNOWLEDGEMENT: This study was supported by a Canadian Institutes of Health Research (CIHR)/Saskatchewan Health Services Research Foundation grant. It was also supported by a CIHR Career Investigator Award to Thomas Hadjistavropoulos and a CIHR-funded post-doctoral fellowship to Ronald Martin. The suggestions of Jaime Williams are gratefully acknowledged.

12. Crombez G, Vlaeyen JW, Heuts PH, Lysens R. Pain-related fear is more disabling than pain itself: Evidence on the role of pain-related fear in chronic back pain disability. Pain 1999;80:329-39.

13. McCracken LM, Zayfert C, Gross RT. The Pain Anxiety Symptoms Scale (PASS): A multi-modal measure of pain-specific anxiety symptoms. Behav Ther 1993;16:183-4.

14. Vlaeyen JW, Kole-Snijders AM, Boeren RG, van Eek H. Fear of movement/(re)injury in chronic low back pain and its relation to behavioural performance. Pain 1995;62:363-72.

15. Waddell G, Newton M, Henderson I, Somerville D, Main CJ. A Fear Avoidance Beliefs Questionnaire (FABQ) and the role of fear-avoidance in chronic low back pain and disability. Pain 1993;52:157-68.

16. Flint A. Epidemiology and comorbidity of anxiety disorders in the elderly. Am J Psychiatry 1994;6:640-9.

17. Owens KM, Hadjistavropoulos T, Asmundson GJ. Addressing the need for appropriate norms when measuring anxiety in seniors. Aging Ment Health 2001;4:309-14.

18. Reiss S, Peterson RA, Gursky DM, McNally RJ. Anxiety sensitivity, anxiety frequency and the prediction of fearfulness. Behav Res Ther 1986;24:1-8.

19. Beck AT, Steer RA. Manual for the Beck Anxiety Inventory. San Antonio, Texas: The Psychological Corporation, 1993.

20. Asmundson GJ, Kuperos JL, Norton GR. Do patients with chronic pain selectively attend to pain-related information? Preliminary evidence for the mediating role of fear. Pain 1997;72:27-32.

21. McDonald C. An age-specific analysis of the neurosis. Br J Psychiatry 1973;122:477-80.

22. Turnbull JM. Anxiety and physical illness in the elderly. J Clin Psychiatry 1989;50:40-5.

23. Rice DP, MacKenzie EJ, Jones AS, et al. Cost of injury in the United States: A report to congress. San Francisco, California: Institute for 
Health and Aging, University of California and Injury Prevention Center, The Johns Hopkins University, 1989.

24. Nevitt MC. Falls in older persons: Risk factors and prevention. In: Institute of Medicine, ed. The Second Fifty Years: Promoting Health and Preventing Disability. Washington: National Academy Press, 1990:263-90.

25. Hornbrook MC, Stevens VJ, Wingfield DJ, Hollis JF, Greenlick MR, Ory MG. Preventing falls among community-dwelling older persons: Results from a randomized trial. Gerontologist 1994:34:16-23.

26. Tideiksaar R. Falls in the elderly. Bull N Y Acad Med 1988;64:145-63.

27. Tinetti ME, Speechley M, Ginter SF. Risk factors for falls among elderly persons living in the community. N Engl J Med 1988;319:1701-7.

28. Wilkins K. Health consequences of falls for seniors. Health Rep 1999;10:47-55.

29. Rowe JW. Falls. In: Rowe JW, ed. Health and Disease in Older Age. Boston: Little, Brown, 1982:394.

30. Carter ND, Kannus P, Khan KM. Exercise in the prevention of falls in older people: A systematic literature review examining the rationale and the evidence. Sports Med 2001;31:427-38.

31. Roberts BL, Wykle ML. Pilot study results. Falls among institutionalized elderly. J Gerontol Nurs 1993;19:13-20.

32. Soja ME, Kippenbrock TA, Hendrich AL, Nyhuis A. A risk model for patient fall prevention. In: Funk SG, Tornquist EM, Champagne MT, Wiese RA, eds. Key Aspects of Elder Care: Managing Falls, Incontinence and Cognitive Impairment. New York: Springer Publishing Company, 1992:65-9.

33. Arfken CL, Lach HW, Birge SJ, Miller JP. The prevalence and correlates of fear of falling in elderly persons living in the community. Am J Public Health 1994;84:565-70.

34. Howland J, Lachman ME, Walker Peterson E, Cote J, Kasten L, Jette A. Covariates of fear of falling and associated activity curtailment. Gerontologist 1998;5:549-55.

35. Maki BE, Holliday PJ, Topper AK. Fear of falling and postural performance in the elderly. J Gerontol 1991;46:M123-31.

36. Tinetti ME, Richman D, Powell L. Falls efficacy as a measure of fear of falling. J Gerontol 1990;45:P239-43.

37. Bhala RP, O'Donnell J, Thoppil E. Ptophobia. Phobic fear of falling and its clinical management. Phys Ther 1982;62:187-90.

38. Murphy J, Isaacs B. The post-fall syndrome: A study of 36 elderly patients. Gerontology 1982;28:265-70.

39. Vellas B, Cayla F, Bocquet H, de Pemille F, Albarede JL. Prospective study of restriction of activity in old people after falls. Age Ageing 1987;16:189-93.

40. Silverton R, Tideiksaar R. Psychosocial aspects of falls. In: Tideiksaar R, ed. Falling in Old Age: Its Prevention and Treatment. New York: Springer; 1989:87-110.

41. Cumming RG, Salkeld G, Thomas M, Szonyi G. Prospective study of the impact of fear of falling on activities of daily living, SF-36 scores, and nursing home admission. J Gerontol A Biol Sci Med Sci 2000;55:M299-305.

42. Lachman ME, Howland J, Tennstedt S, Jette A, Assmann S, Peterson EW. Fear of falling and activity restriction: The survey of activities and fear of falling in the elderly (SAFE). J Gerontol B Psychol Sci Soc Sci 1998;53:P43-50.
43. Tinetti ME, Powell L. Fear of falling and low self-efficacy: A case of dependence in elderly persons. J Gerontol 1993;48(Spec No):35-8.

44. Tinetti ME, Mendes de Leon CF, Doucette JT, Baker DI. Fear of falling and fall-related efficacy in relationship to functioning among community-living elders. J Gerontol 1994;49:M140-7.

45. Wright BA, Aizenstein S, Vogler G, Rowe M, Miller C. Frequent fallers. Leading groups to identify psychological factors. J Gerontol Nurs 1990;16:15-9.

46. The prevention of falls in later life. A report of the Kellogg International Work Group on the Prevention of Falls by the Elderly. Dan Med Bull 1987;34(Suppl 4):1-24.

47. Tuokko H, Hadjistavropoulos T. An Assessment Guide to Geriatric Neuropsychology. Mahwah, New Jersey: Lawrence Erlbaum Associates, 1998.

48. Powell LE, Myers AM. The Activities-specific Balance Confidence (ABC) Scale. J Gerontol A Biol Sci Med Sci 1995;50A:M28-34.

49. Margolis RB, Tait RC, Krause SJ. A rating system for use with patient pain drawings. Pain 1986;24:57-65.

50. Kerns RD, Turk DC, Rudy TE. The West Haven-Yale Multidimensional Pain Inventory (WHYMPI). Pain 1985;23:345-56.

51. Kori SH, Miller RP, Todd DD. Kinisiophobia: A new view of chronic pain behavior. Pain Manage 1990;3:35-43.

52. McNeil DW, Rainwater AJ III. Development of the Fear of Pain Questionnaire - III. J Behav Med 1998;21:169-90.

53. Bentler PM. EQS: Structural Equation Program Manual. Los Angeles: Multivariate Software Inc, 2005.

54. Byrne BM. Structural Equation Modeling with EQS and EQS/Windows: Basic Concepts, Applications, and Programming. Thousand Oaks, California: Sage, 1994.

55. Hu L, Bentler PM. Fit indices in covariance structure modeling: Sensitivity to underparameterized model mis-specification. Psychol Methods 1998;3:424-53.

56. Browne MW, Cudeck R. Alternate ways of assessing model fit. In: Bollen KA, Long JS, eds. Testing Structural Equation Models. Newbury Park, California: Sage, 1993:136-62.

57. Marsh HW, Balla JR, McDonald RP. Goodness-of-fit indexes in confirmatory analysis: The effect of sample size. Psychol Bull 1988;103:391-410.

58. Williams J, Hadjistavropoulos T, Asmundson GJ. The effects of age and fear of pain on attentional and memory biases relating to pain and falls. Anxiety, Stress and Coping 2005;18:53-69.

59. Hadjistavropoulos T, Lints A, Martin R, Asmundson GJ. A six month longitudinal investigation of pain, fear of pain and fear of falling among seniors. J Pain 2005; (Suppl 1):131. (Abst)

60. Roelofs J, Peters ML, Fassaert T, Vlaeyen JW. The role of fear of movement and injury in selective attentional processing in patients with chronic low back pain: a dot-probe evaluation. J Pain 2005;6:294-300.

61. Dehghani M, Sharpe L, Nicholas MK. Selective attention to painrelated information in chronic musculoskeletal pain patients. Pain 2003;105:37-46.

62. Keefe FJ, Rumble ME, Scipio CD, Giordano LA, Perri LM. Psychological aspects of persistent pain: Current state of the science. J Pain 2004;5:195-211. 


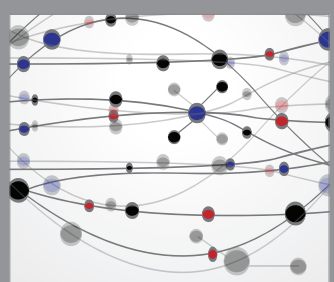

The Scientific World Journal
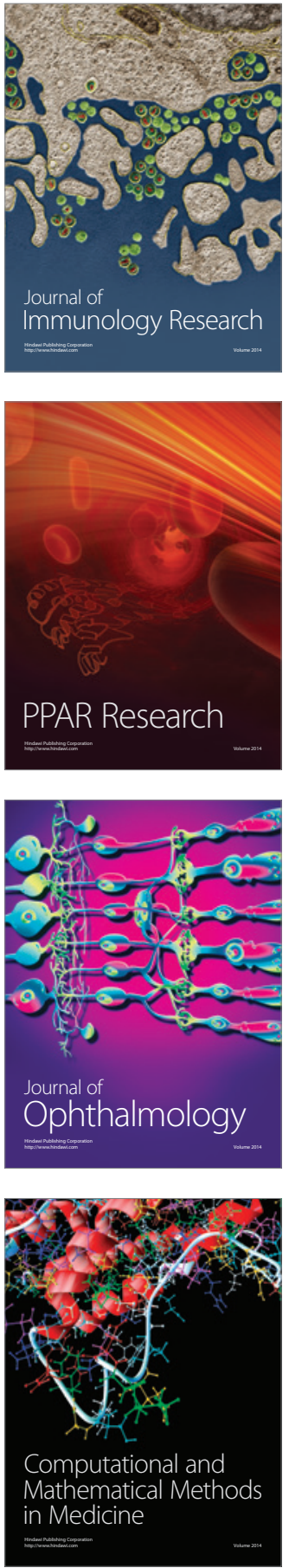

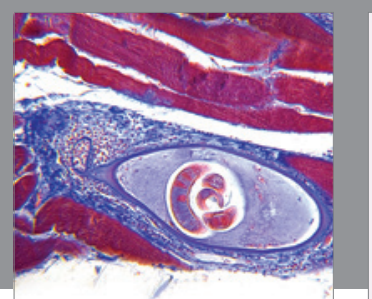

Gastroenterology Research and Practice

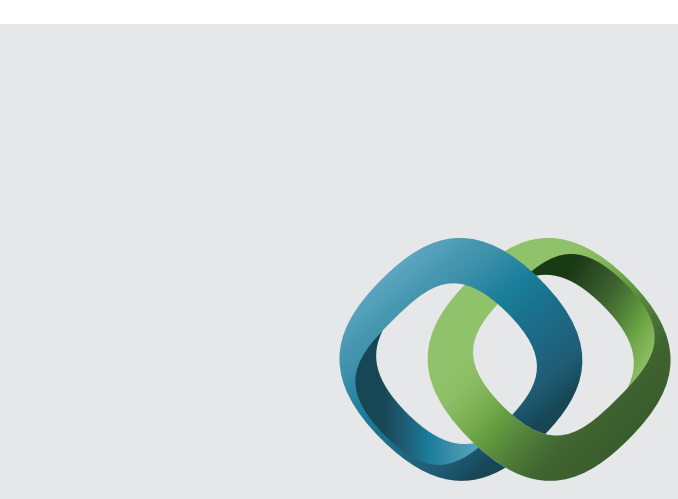

\section{Hindawi}

Submit your manuscripts at

http://www.hindawi.com
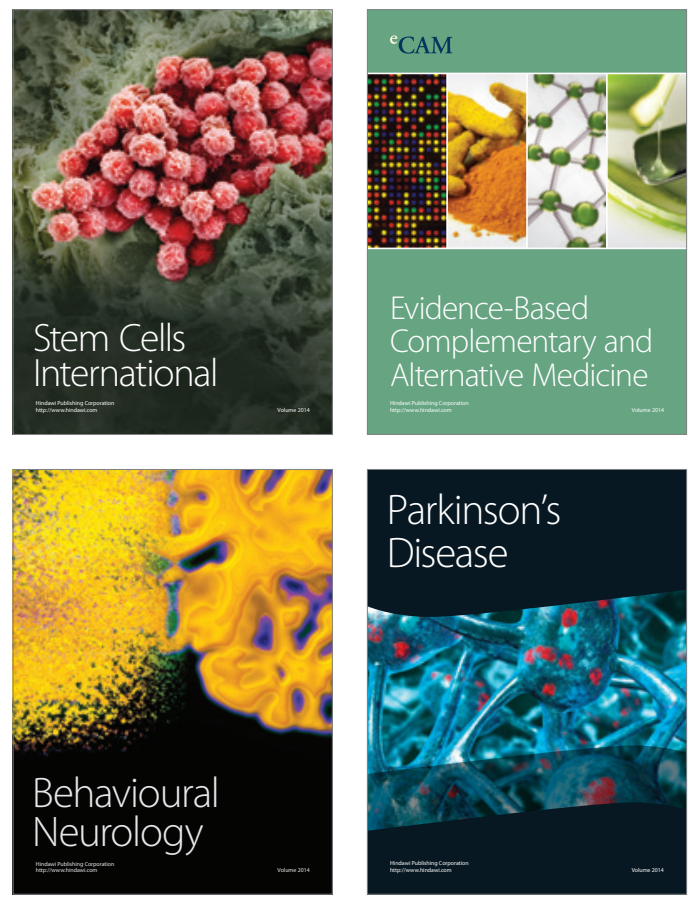
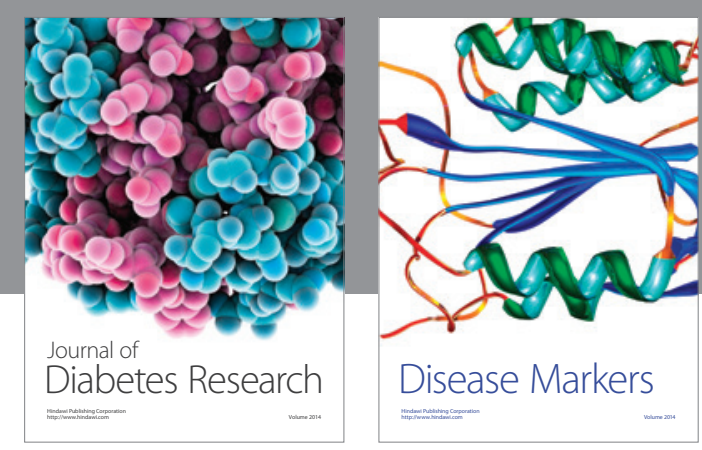

Disease Markers
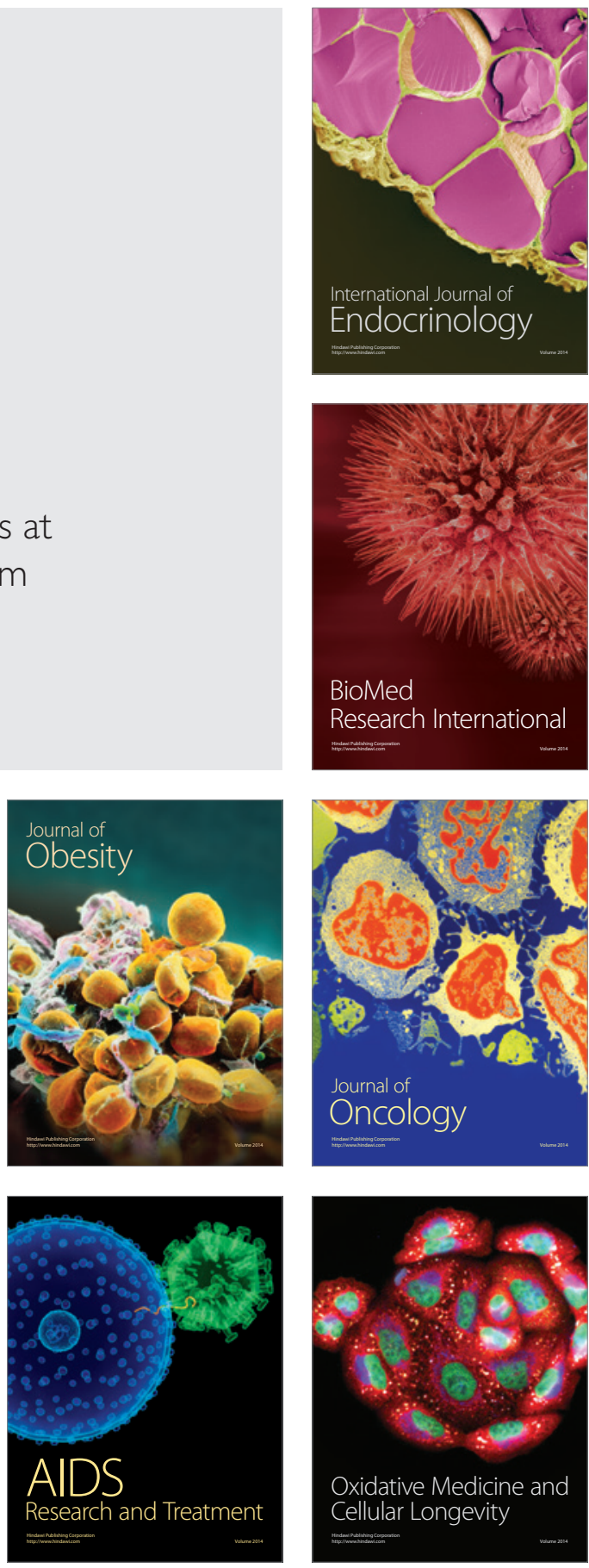